\title{
QUASI Z-SOURCE MULTILEVEL DC-DC STEP-UP CONVERTER WITH MEDIUM FREQUENCY AC ISOLATION FOR DC POWER COLLECTION SYSTEM OF PV SYSTEM
}

\author{
Nimrah Saeed \\ Department of Electrical Engineering \\ Shanghai Jiao Tong University \\ Shanghai, China \\ Lubna Majeed \\ Department of Electrical Engineering \\ HITEC university Taxila
}

\begin{abstract}
This paper presents advanced step-up dc/dc converter intended for high voltage gains for distributed power generation systems. A novel topology named Quasi Z-source Multilevel DC-DC step-up isolated Converter (ML-qZDC) has been proposed in this paper. Here, the ML-qZDC based Photovoltaic (PV) array system with MPPT technique for medium frequency has been introduced. Two active bridges can produce any desired output voltage waveform across the transformer. $A$ 7L-2L configuration has been investigated and affirmed on SIMULINK MATLAB to verify the proposed topology. The proposed topology in this paper has proved that, high quality boosted DC output is obtained with low harmonic distortion. The experimental results have proved the validity and effectiveness of this converter. The proposed scheme has a potential application in case of large scaled DC PV stations.
\end{abstract}

Keywords - Cascaded H-bridge (CHB); dual active bridge (DAB); multilevel converter; shoot through state

\section{INTRODUCTION}

Significance of renewable energy sources is enhancing progressively due to increasing power consumption. On account of depleting fossil fuel reserves and global climate changes sustainable energy infra-structure is an essential requirement. Distributed generation systems with power inverters are recent research topic with assorted circuit topologies proposed and diverse control methods suggested. Nowadays, industry demands for higher power equipment connected with medium voltage network. However, it is difficult to connect a semiconductor switch directly to the grid. For this reason, multilevel converters are required to work with high voltage level.

\author{
Anas Ibrar \\ Department of Electrical Engineering \\ University of Wah \\ Wah Cantt, Pakistan \\ Asmaa Mehmood \\ Department of Electrical Engineering \\ Air University
}

Photovoltaic (PV) power generation systems are very promising nowadays because of numerous benefits like low weight, best high temperature performance, low cost, flexibility and many more. Still, installation cost and variability of PV module limits its wide range applications. PV module's voltage is not constant because it varies with temperature and radiations, therefore conventional voltage and current source converters are not suitable for this topology. So,to keep cope with PV generation systems, transformers or DC-DC converters are usually used [1].

Z-source converters (ZSC) are considered most suitable for PV generation systems due to its ability of boosting and conversion in one stage. Recently, many topologies are derived from ZSC to further improve its capabilities. Voltage fed, quasi source topology is introduced in this paper. Quasi $\mathrm{Z}$-source converter (qZSC) can handle varied voltage range and it also draws constant current from PV modules. As compared to conventional ZSC, qZSC can reduce source stress and lower components are required for this converter. Basic topology of quasi Z-source impedance network is shown in Fig.1.

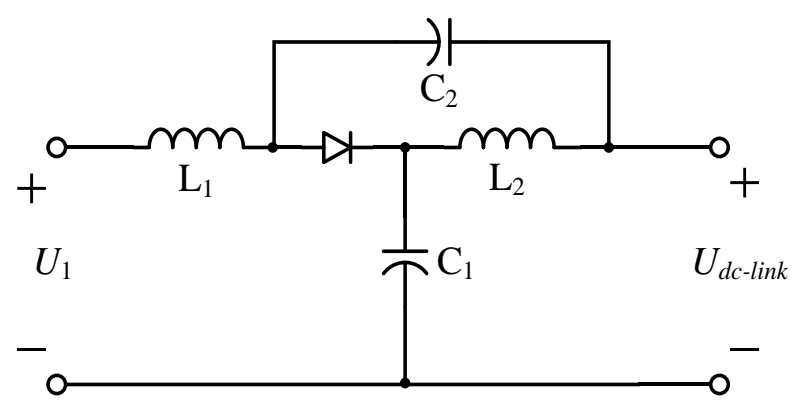

Fig.1. Quasi Z-source Impedance Network 
Grid connected PV array systems are very renowned now a days. These networks keep track of maximum power point (MPPT) of system and increase the injected energy of the grid. For medium and high voltage applications, Dual Active Bridge (DAB) converter associated with multilevel H-bridge network is recommended. Due to smoothness and modularity of control, multilevel inverters have expected special attention in past few years. These converters can provide low harmonic distortion, filtering components with less weight and increased power capacity. There are three firm ways to multilevel H-bridge i.e. Cascaded H-bridge (CHB), flying capacitor (FC) and neutral point clamped (NPC) as shown in Fig 1. Multilevel inverters can be classified into two groups [2-6].

- Symmetric ; voltage sources have same magnitude

- Asymmetric; different voltage sources

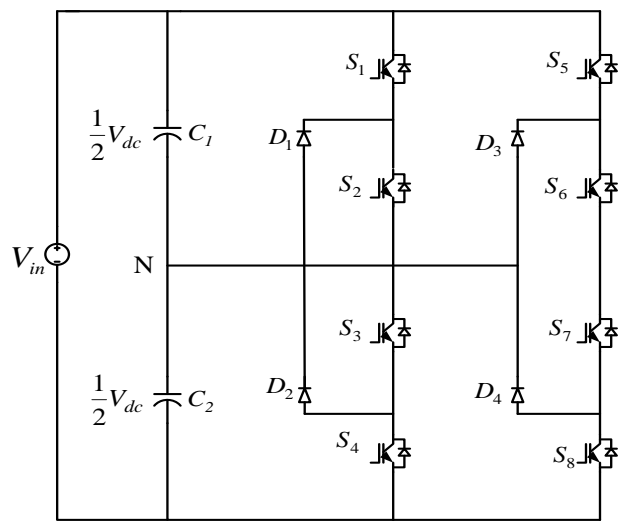

Fig.2 (a) Neutral Point Clamped

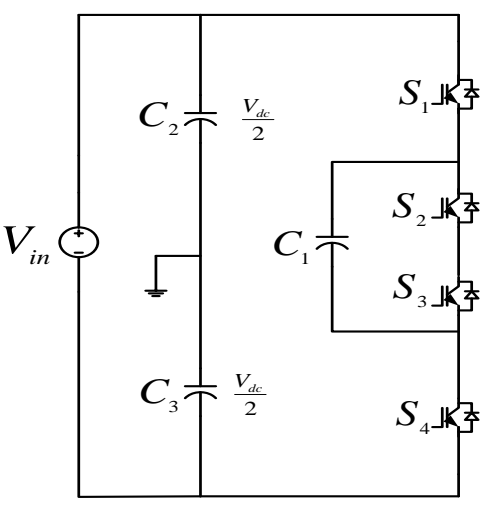

Fig.2 (b) Flying Capacitor topology

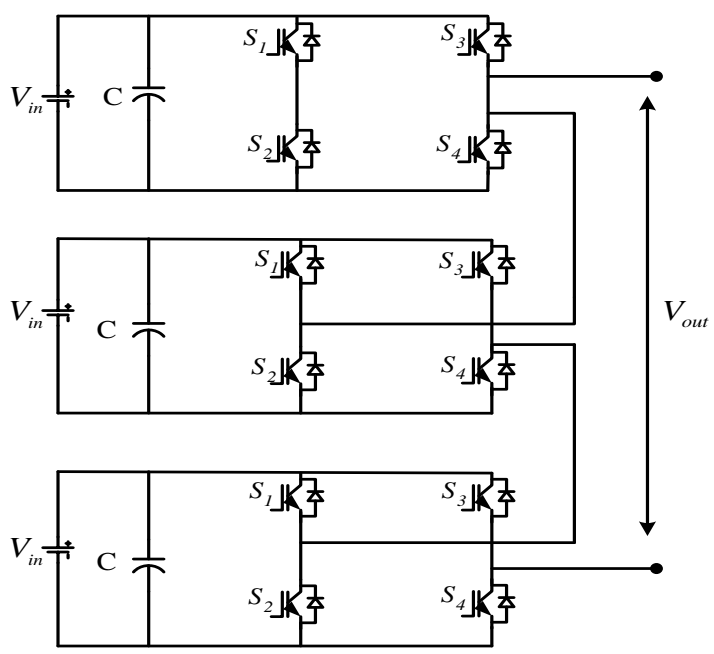

Fig.2 (c) Cascaded H-bridge topology

In this paper, a novel topology named Quasi- Z-source multilevel DC-DC converter (ML-qZDC) is proposed. The converter is multilevel through symmetric CHB topology. Reliability and buck/boost capability is supplementary in this topology by introducing qZ-source impedance network. qZ-source impedance network operates in two modes i.e. shoot through state and non-shoot through state as shown in Fig.3. Examination of circuit demonstrations that during non-shoot through state voltage across inductor, capacitor and diodes can be expressed as [1]

$$
\begin{gathered}
v_{L 1}=V_{\text {in }}-v_{C 1}, v_{L 2}=-v_{C 1} \\
V_{\text {out }}=v_{C 1}-v_{L 2}=v_{C 1}+v_{C 2} \\
v_{d}=0
\end{gathered}
$$

Where, $v_{L 1}, V_{C 1}$ and $V_{C 2}$ represents the voltage across inductor 1 and capacitor 1 and 2 respectively. $v_{d}$ is voltage across diode, $V_{\text {in }}$ and $V_{\text {out }}$ stands for input and output voltages of the circuit. During shoot through state, output terminals of network are shorted by a switch, which reversebias the diode in impedance network.

$$
\begin{gathered}
v_{L 1}=v_{C 2}+V_{\text {in }}, \quad v_{L 2}=v_{C 1} \\
v_{d}=v_{C 1}+v_{C 2} \\
V_{\text {out }}=0
\end{gathered}
$$

From (1) and (4), inductor and capacitor voltages during one switching cycle in steady state can be given as

$$
v_{L 1}=\frac{T_{0}\left(v_{C 2}+V_{i n}\right)+T_{1}\left(V_{i n}-v_{C 1}\right)}{T}=0
$$




$$
\begin{gathered}
v_{L 2}=\frac{T_{0}\left(v_{C 2}\right)+T_{1}\left(-v_{C 1}\right)}{T}=0 \\
v_{C 1}=\frac{T_{1}}{T_{1}-T_{0}} V_{i n} \\
v_{C 2}=\frac{T_{0}}{T_{1}-T_{0}} V_{i n}
\end{gathered}
$$

$T$ represents the one switching cycle, $T_{0}$ and $T_{1}$ is interval during shoot through state and non-shoot through state respectively. Therefore $T=T_{0}+T_{1}$ and shoot through duty ratio can be expressed as

$$
D=\frac{T_{0}}{T}
$$

The peak DC voltage across converter topology can be found as

$$
\begin{gathered}
V_{\text {out }}=\frac{T_{1}}{T_{1}-T_{0}} V_{\text {in }}+\frac{T_{0}}{T_{1}-T_{0}} V_{\text {in }}=\frac{T}{T_{1}-T_{0}} V_{\text {in }} \\
V_{\text {out }}=\frac{1}{1-2 \frac{T_{0}}{T}} V_{\text {in }}, B=\frac{1}{1-2 \frac{T_{0}}{T}} \\
V_{\text {out }}=B V_{\text {in }}
\end{gathered}
$$

Where, $B$ is boost factor of qZSC. Power rating of system is expressed by $P$ and average current across capacitors can be calculated as

$$
i_{C 1}=i_{C 2}=\frac{P}{V_{i n}}
$$

Quasi Z-source converter is particularly suitable for PV generation systems because it can draw constant and continuous current from the source. qZSC inherits all the benefits of ZSC and it also has its own advantages like voltage on capacitor $C_{2}$ is lower in qZSC as compared to ZSC. Moreover, input stress of qZSC is less because of inductor $L_{1}$ and a common DC rail exists between source and converter.

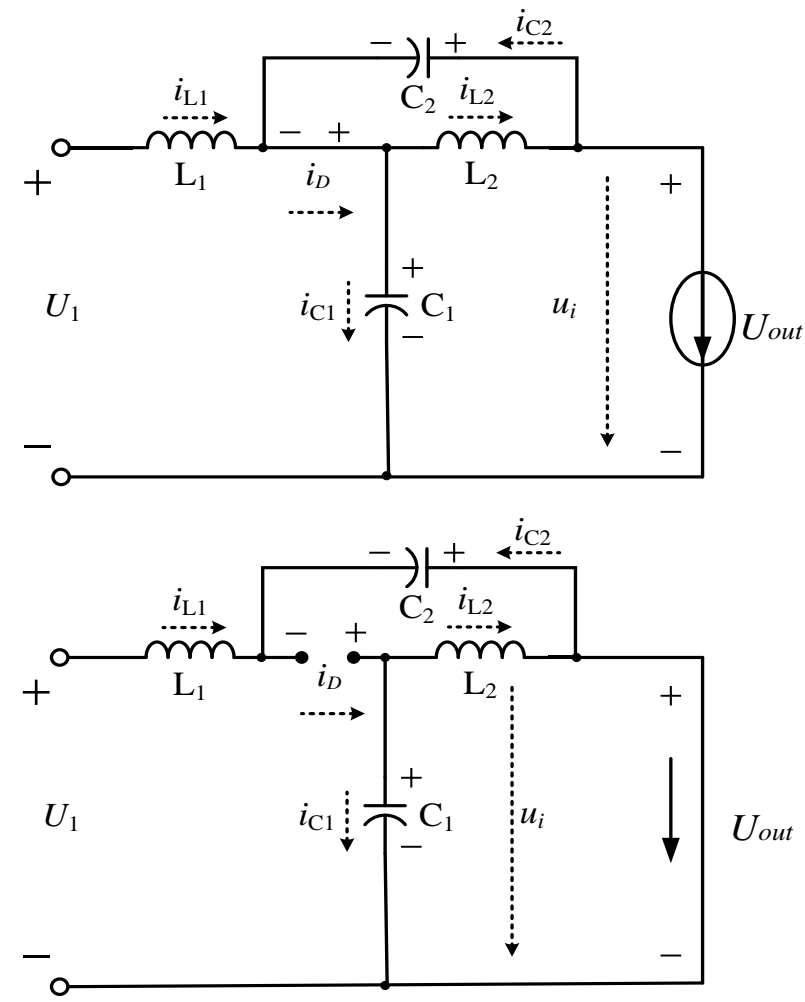

Fig.3. Shoot through and non-shoot through states

Numbers of H-bridge cells are connected in series supplied by DC sources. Effective switching state of multilevel inverter can be related to switching state of individual cell. Similarly, product of all voltage levels of individual cell is voltage level of multilevel inverter.

$$
V_{0_{t o t}}=V_{01}+V_{02}+\ldots \ldots . . V_{0 n}
$$

Maximum number of voltage levels for symmetric DC voltages can be given by

$$
L=2 n+1
$$

Where, number of levels are represented by $L$ and $n$ is number of series connected inverters. In CHB network Modulation index for $\mathrm{H}$-bridge inverter is [7]

$$
M=\frac{\sqrt{2} V_{0}}{V_{d c}}
$$

Where, $V_{0}$ is magnitude of inverter output voltage and $V_{d c}$ is DC voltage applied to the inverter. Following are some merits of multilevel converters

- High quality output voltage

- Raise robustness 
- Increase efficiency

- Lower harmonic component

- Minor switching losses

- Less $\frac{d v}{d t}$

- Reduce electromagnetic interference

The rest of paper is divided into four sections. Section 2 represents the proposed topology of quasi Z-source multilevel isolated DC-DC topology. Experimental verification and discussion about results are shown in section 3. Conclusion is drawn in section 4 and acknowledgement is presented in section 5 .

\section{PROPOSED TOPOLOGY}

Fig.4. shows the proposed model of ML-qZDC. Shoot through state is inserted in this topology and the added impedance network prevents damaging of switches from sudden current surge. Two active bridges can produce "X"L-2L DC voltage waveforms across the high frequency transformer. " $\mathrm{X}$ " can be 3, 5, 7, 9 etc. Only positive forward flow is discussed in this paper. Fig.5. shows the equivalent circuit of an individual cell of inverter to demonstrate the normal switching state [8-10]

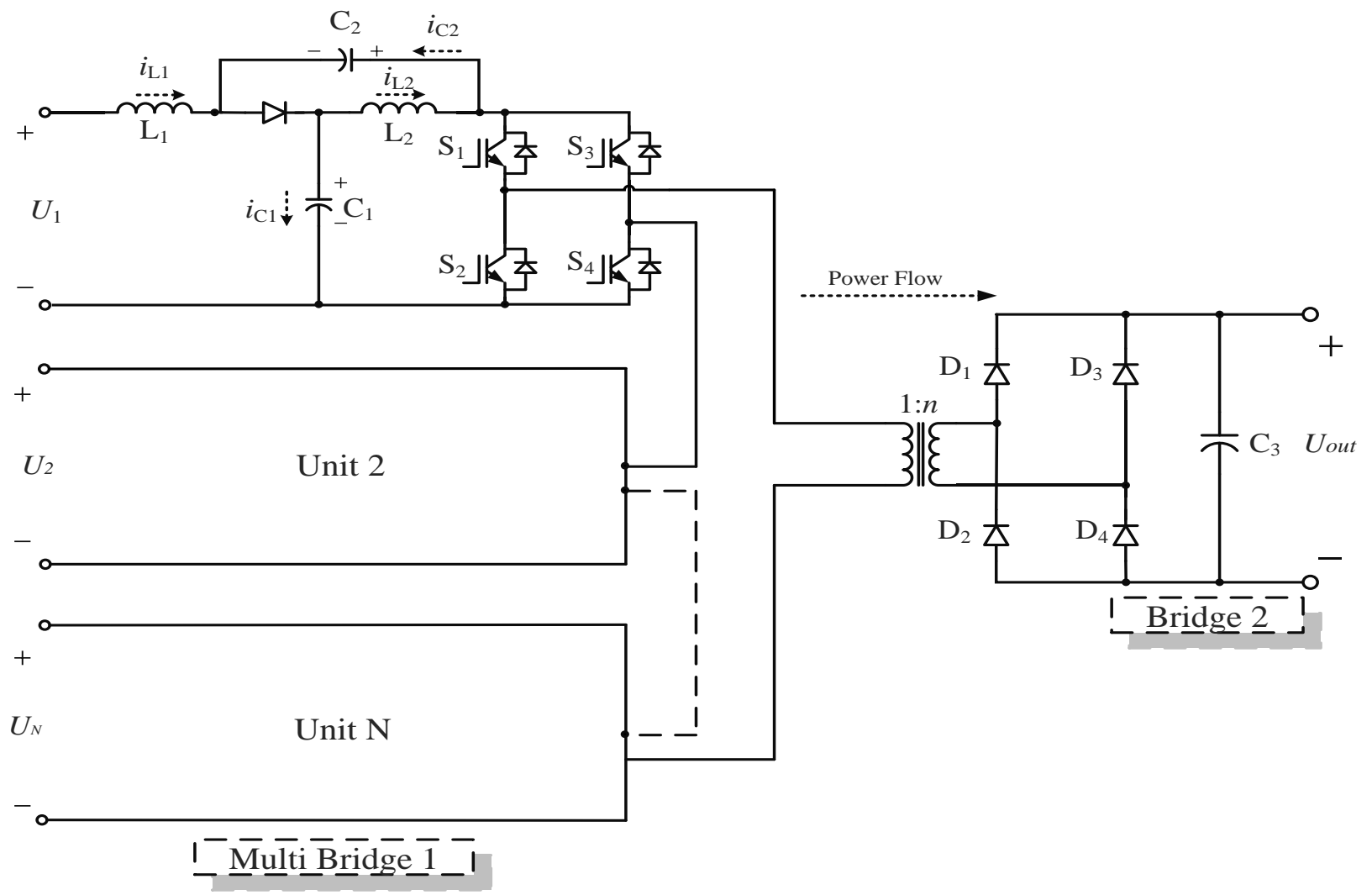

Fig. 4. Quasi Z-source Multilevel DC-DC step-up isolated Converter

Both power of $V_{\text {in }}$ and stored energy of inductors $L_{1}$ and $L_{2}$ is transferred to the H-bridge. At the same time, power is also transferred to boost the consumed energy of capacitors $C_{1}$ and $C_{2}$ during shoot through state [11].

Bridge 1 converts the DC input voltage into AC voltage and transforms it from primary side of transformer to secondary side. The switches of other bridge are turned off and diodes $D_{1}-D_{4}$ work as a rectifier to again convert $\mathrm{AC}$ into DC voltage.

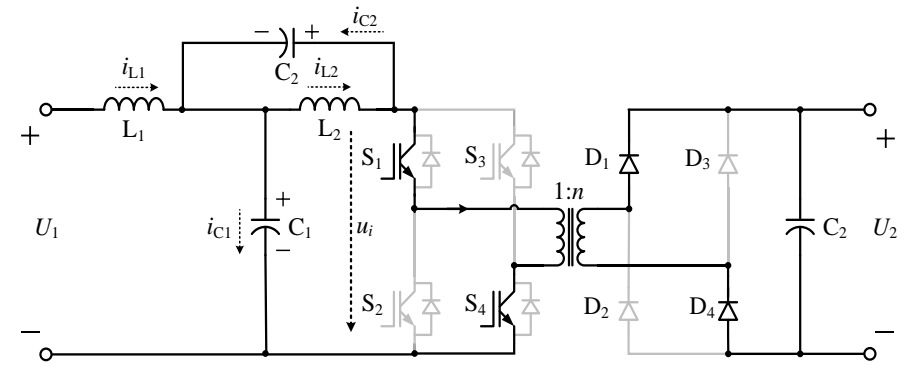

Fig. 5. switching state of single cell 


\section{International Journal of Engineering Applied Sciences and Technology, 2019 \\ Vol. 4, Issue 5, ISSN No. 2455-2143, Pages 13-18 \\ Published Online September 2019 in IJEAST (http://www.ijeast.com)}

\section{SimUlations AND DISCUSSION}

A novel topology named quasi Z-source multilevel DC-DC converter is presented in this paper. In order to validate the proposed model, some simulations have been done on MATLAB. 7L-2L topology has been examined and verified in this paper. Impedance network parameters are $L_{1}=L_{2}=$ $0.1 \times 10^{-3} \mathrm{H}$ and $C_{1}=C_{2}=220 \times 10^{-6} \mathrm{~F}$. Nominal power and frequency of transformer is $4000 \mathrm{VA}$ and $10 e^{3}$. Each individual cell is given $800 \mathrm{~V}$ so, the input voltages given to this topology is $2400 \mathrm{~V}$.

MPP tracking is used to control the proposed topology. The amount of sunlight fallen on PV panels and characteristics of load are key factors which effect the efficiency of power transfer. The efficiency of load characteristic that provides the maximum power transfer varies with the change of intensity of sunlight. The characteristics of load which changes to keep power transfer at maximum efficiency are optimized. This point is called the maximum power point and the process of finding this point is known as MPPT.I-V curves of PV cells where a line intersects the knee of the curves is the maximum power transfer point as shown in Fig.6.

The output waveform obtained from ML-qZDC is shown in Fig.7. Stable DC output is obtained in between $5000 \mathrm{~V}$ to $6000 \mathrm{~V}$.

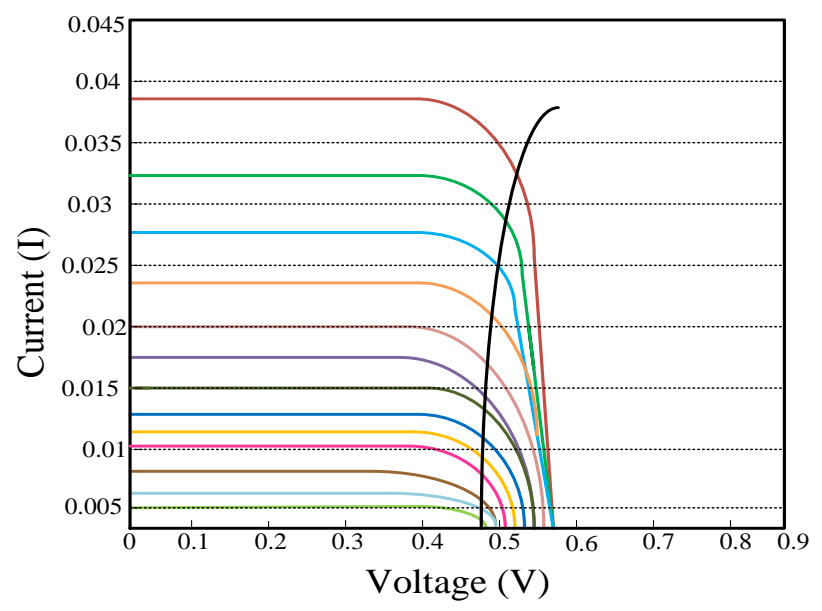

Fig. 6. I-V curve of MPPT

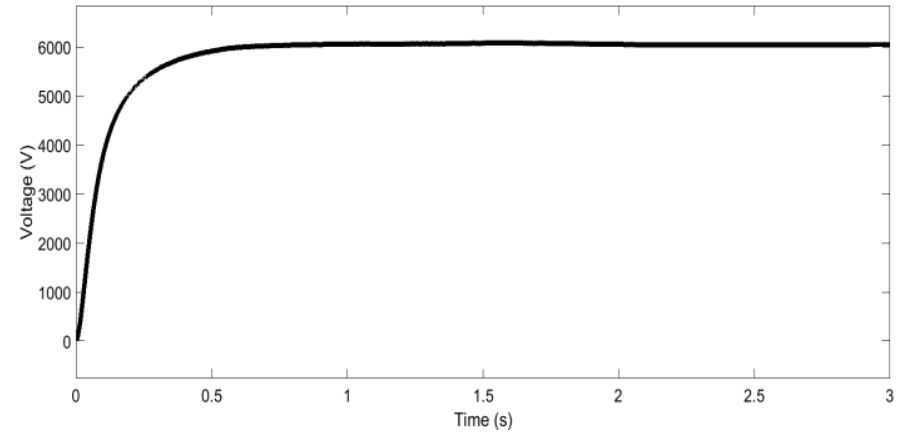

Fig. 7. DC output voltage

\section{CONCLUSION}

ML-qZDC is a novel topology which is proposed and analyzed in this paper. The performance and operation of 7L-2L topology is verified on MATLAB. The proposed topology in this paper has proved that, high quality boosted DC output can be obtained on secondary side of transformer with low harmonic distortion and less switching losses. Favorable load voltage working can be attained from multilevel Z-source converter. Quasi Z-source DC-DC step-up converter used medium frequency for power collection of DC output of PV systems.

\section{REFERENCES}

[1] Li Y. , Anderson J., Peng F. Z., and Liu D. (2009), "Quasi-Z-source inverter for photovoltaic power generation systems," 2009 Twenty-Fourth Annual IEEE Applied Power Electronics Conference and Exposition, pp. 918-924.

[2] Alonso A.R., Sebastian J., Lamar D. G., Hernando M.M. and Vazquez A. (2010), "An overall study of a dual active bridge for bidirectional DC/DC conversion," IEEE Energy Conversion Congress and Exposition, pp. 1129 -1135 .

[3] Kiruthiga S.S., and Rajasekaran S. (2011), "A cascaded dual buck half-bridge inverter for efficient power flow control in grid," IOSR Journal of Electrical and Electronic Engineering, pp. 8-13.

[4] Moonem M.A.,Pechacek C.L., Hernandez R., and Krishnaswami H.(2015), "Analysis of a multilevel dual active bridge (ML-DAB) DC-DC converter using symmetric modulation," Electronics 2015, pp.239-260.

[5] Thakur A, Roy R and Dixit T.V. (2015), "Novel 5 level cascaded H-bridge multilevel inverter topology," International Journal of Engineering Trends and Technology (IJETT), pp. 271-274,

[6] Moonem M.A. and Krishnaswami H.(2012), “Analysis and control of multi-level dual active bridge DC-DC 
converter," IEEE Energy Conversion Congress and Exposition (ECCE), pp. $1556-1561$.

[7] Hosseini S.H.,Oskouei A.B., and Dehghanzadeh A.R.(2012), "Multilevel Z-source inverter based SVC algorithm," Control, Automation and Systems (ICCAS), pp. 1512-1517.

[8] Joshi P., Yadav S., and Lokhande M. (2014), "Simulation of seven level $\mathrm{H}$ bridge cascade inverter based on space vector pulse width modulation technique using simulink." International Journal of Current Engineering and Technology.

[9] Perez.M.A, Cortes P., and Rodriguez J. (2008), "Predictive control algorithm technique for multilevel asymmetric cascaded H-bridge inverters, " IEEE Transactions on Industrial Electronics, pp. $4354-4361$.

[10] Thakur A., Roy R., and Dixit T.V. (2015), "Novel 5 level cascaded H-bridge multilevel inverter topology." International Journal of Engineering Trends and Technology (IJETT).

[11] Zhao B., Yu Q., Leng Z., and Chen X. (2011), "Switched
Z-source isolated bidirectional DC-DC converter and its phase-shifting shoot-through bivariate coordinated control strategy," IEEE Trans. on Industrial Electronics, pp. 4657 -4670 . 